\title{
Different Designs of Feeding Aids for Cleft Palatal Defects
}

\section{Anshul Chugh $^{1 *}$, Divya Dahiya ${ }^{1}$, Harleen Thukral' ${ }^{1}$, Sunita Verma ${ }^{1}$, Anamika Ahlawat $^{1}$ and Amit Dahiya ${ }^{2}$}

${ }^{1}$ Department of Prosthodontics and Crown and Bridge, Pandit Bhagwat Dayal Sharma Post Graduate Institute of Dental Sciences, Rohtak, Haryana, India ${ }^{2}$ Department of Orthodontics, Pandit Bhagwat Dayal Sharma Post Graduate Institute of Dental Sciences, Rohtak, Haryana, India

*Corresponding author: Dr. Anshul Chugh, MDS, Associate Professor, Department of Prosthodontics and Crown and Bridge, Pandit Bhagwat Dayal Sharma Post Graduate Institute of Dental Sciences, India, Tel: +9101262213007; E-mail: dr.anshulchugh@rediffmail.com

Received June 13, 2016; Accepted August 01, 2016; Published August 03, 2016

\section{Retraction Note:}

The article entitled "Different Designs of Feeding Aids for Cleft Palatal Defects" has been accepted for publication in the Journal of Health Education Research \& Development considering the statements provided in the article as personal opinion of the author which was found not having any conflict or biasness towards anything. As the article was a perspective one, information provided by the author was considered as an opinion to be expressed through publication. Publisher took decision to make the article online solely based on the reviewers suggestion which considered the article not but a personal opinion of the author. However, it is found that the author have some personal concerns and issues, therefore, being retracted from the journal. 